\title{
Incidence and Risk Factors of Recurrent Venous Thromboembolism after Pulmonary Embolism
}

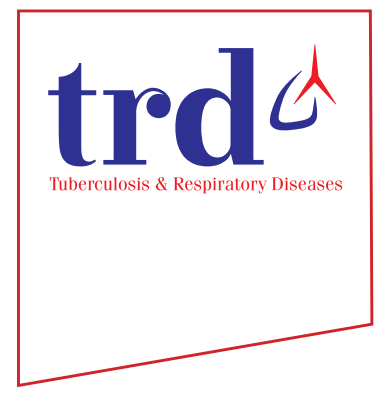

\begin{abstract}
Hun-Gyu Hwang, M.D. ${ }^{1, *(1)}$, Won-Il Choi, M.D. ${ }^{2, *}$, Bora Lee, M.S. ${ }^{3}$ and Choong Won Lee, M.D. ${ }^{4}$ ${ }^{1}$ Respiratory Division, Department of Internal Medicine, Soonchunhyang University Gumi Hospital, Gumi, ${ }^{2}$ Department of Medicine, Keimyung University Dongsan Hospital, Daegu, ${ }^{3}$ Department of Biostatistic Consulting, Soonchunhyang University Bucheon Hospital, Bucheon, ${ }^{4}$ Department of Occupational and Environmental Medicine, Sungso Hospital, Andong, Korea
\end{abstract}

Background: Information about the epidemiology of venous thromboembolism (VTE) recurrence in Korea is lacking. The purpose of this study was to investigate VTE cumulative recurrence rates and identify risk factors for VTE recurrence among Korean adults.

Methods: A retrospective cohort study was conducted on adult patients ( $\geq 18$ years) admitted to a university teaching hospital for pulmonary embolism (PE) from 2005 to 2013. The main outcome of interest was a recurrence of VTE. We used Cox proportional hazard regression analyses to calculate the relative risk of VTE recurrence.

Results: Five-year cumulative incidence of recurrent VTE events was 21.5\% (95\% confidence interval [CI], 17.7-25.4) in all cases of PE; $17 \%$ after provoked and $27 \%$ after unprovoked PE. Multivariate analysis showed that body mass index (BMI) of $\geq 25$ (hazard ratio [HR], 2.02; 95\% CI, 1.17-3.46; $\mathrm{p}=0.01$ ) and longer anticoagulation therapy duration (HR, 0.90; 95\% CI, 0.84-0.96; $\mathrm{p}<0.01$ ) were independently associated with risk of VTE recurrence. Risk factors not found to be statistically significant at the $<0.05$ level included history of VTE (HR, 1.81; 95\% CI, 0.84-3.88; $\mathrm{p}=0.12$ ), unprovoked PE (HR, 1.70; 95\% CI, 0.89-3.25; $\mathrm{p}=0.10$ ), symptomatic deep vein thrombosis (HR, 1.62; 95\% CI, 0.89-2.94; $\mathrm{p}=0.10$ ), and female sex (HR, 1.42; 95\% CI, 0.78-2.55; $\mathrm{p}=0.24$ ). We found that age, history of cancer, and other co-morbidities did not significantly affect the risk of VTE recurrence.

Conclusion: Recurrence of VTE after PE is high. Patients with BMI $\geq 25$ or reduced anticoagulation therapy duration have a higher risk of recurrent VTE.

Keywords: Pulmonary Embolism; Recurrence; Venous Thromboembolism

Address for correspondence: Won-II Choi, M.D.

Department of Medicine, Keimyung University Dongsan Hospital, 56

Dalseong-ro, Jung-gu, Daegu 41931, Korea

Phone: 82-53-250-7572, Fax: 82-53-250-8379

E-mail: wichoi@dsmc.or.kr

*Hun-Gyu Hwang and Won-II Choi contributed equally to this work.

Received: Mar. 4, 2019

Revised: Apr. 21, 2019

Accepted: May. 17, 2019

Published online: May. 31, 2019

(c) It is identical to the Creative Commons Attribution Non-Commercial License (http://creativecommons.org/licenses/by-nc/4.0/).

Copyright $\odot 2019$

The Korean Academy of Tuberculosis and Respiratory Diseases.

\section{Introduction}

Venous thromboembolism (VTE) is a common, lifethreatening disease that can frequently recur and cause long term complications. VTE comprises deep venous thrombosis (DVT) and/or pulmonary embolism (PE). The clinical presentation of about two-thirds of VTE cases is DVT, and the remaining one third present with $\mathrm{PE}^{1}$.

VTE is an important safety issue in patients who are on anticoagulation therapy. Early and long-term management is essential in order to prevent complications including recurrence of VTE, chronic thromboembolic pulmonary hypertension (CTEPH), and post thrombotic syndrome (PTS). The incidence of VTE in Asia is than in Western countries, but a recent 
retrospective study in the Korean population demonstrated an annual increasing incidence of $\mathrm{VTE}^{2}$.

In the western world, VTE is the third most common cardio- vascular disease, following myocardial infarction and stroke $\mathrm{s}^{3,4}$. Unlike in Western countries, the incidence of VTE in Korea is low, but it is increasing every year ${ }^{2,5}$. In addition, elderly

Table 1. Characteristics of the patients with PE as a first or recurrent VTE event

\begin{tabular}{|c|c|c|c|}
\hline Parameter & Recurrent VTE (n=68) & First PE ( $n=594)$ & p-value \\
\hline Age, yr & $65.6 \pm 12.8$ & $67.6 \pm 12.4$ & 0.228 \\
\hline Age, yr & & & 0.693 \\
\hline$\leq 49$ & $9(13.2)$ & $59(9.9)$ & \\
\hline $50-59$ & $8(11.8)$ & $77(13.0)$ & \\
\hline $60-69$ & $16(23.5)$ & $137(23.1)$ & \\
\hline $70-79$ & $30(44.1)$ & $246(41.4)$ & \\
\hline$>80$ & $5(7.4)$ & $75(12.6)$ & \\
\hline Sex & & & 0.039 \\
\hline Men & $22(32.4)$ & $270(45.5)$ & \\
\hline Women & $46(67.6)$ & $324(54.5)$ & \\
\hline $\mathrm{BMI}, \mathrm{kg} / \mathrm{m}^{2}$ & & & $<0.001$ \\
\hline$\geq 25$ & $34(55.7)$ & $177(32.4)$ & \\
\hline$<25$ & $27(44.3)$ & $370(67.6)$ & \\
\hline Diagnosis & & & 0.322 \\
\hline $\mathrm{PE}+\mathrm{DVT}$ & $30(44.1)$ & $259(43.6)$ & \\
\hline PE only & $38(55.9)$ & $365(61.4)$ & \\
\hline \multicolumn{4}{|l|}{ Co-morbidity } \\
\hline Heart failure & $11(16.2)$ & $62(10.4)$ & 0.152 \\
\hline Respiratory failure & $34(50.0)$ & $343(57.7)$ & 0.222 \\
\hline Renal dysfunction & $6(8.8)$ & $62(10.4)$ & 0.678 \\
\hline COPD & $2(2.9)$ & $23(3.9)$ & 0.703 \\
\hline Active cancer & $8(11.8)$ & $186(31.3)$ & 0.001 \\
\hline Autoimmune & $1(1.5)$ & $9(1.5)$ & 0.977 \\
\hline Diabetes & $10(14.7)$ & $108(18.2)$ & 0.478 \\
\hline Previous DVT or PE & $9(13.2)$ & $43(7.2)$ & 0.082 \\
\hline Symptomatic DVT & $30(44.1)$ & $167(28.1)$ & 0.006 \\
\hline Diagnosis & & & 0.277 \\
\hline Provoked & $53(77.9)$ & $426(71.7)$ & \\
\hline Unprovoked & $15(22.1)$ & $168(28.3)$ & \\
\hline Anticoagulation duration, mo & & & 0.002 \\
\hline$<3.0$ & $23(33.8)$ & $244(41.1)$ & \\
\hline $3.0-6.0$ & $25(36.8)$ & $112(18.9)$ & \\
\hline$>6.1$ & $20(29.4)$ & $238(40.1)$ & \\
\hline Follow-up duration, mo & $17.0(30.0)$ & $18.0(51.0)$ & 0.659 \\
\hline \multicolumn{4}{|l|}{ Outcome } \\
\hline Mortality & $16(23.5)$ & $141(23.7)$ & 0.970 \\
\hline
\end{tabular}

Values are presented as mean \pm SD or number $(\%)$.

PE: pulmonary embolism; VTE: venous thromboembolism; BMI: body mass index; DVT: deep vein thrombosis; COPD: chronic obstructive pulmonary disease; SD: standard deviation. 
women in Korea have almost the same incidence of VTE as that found in the West ${ }^{6,7}$.

Complications of VTE include PTS and CTEPH. PTS is a chronic venous insufficiency characterized by pain, swelling, and ulceration. It has been reported that PTS occurs in $20 \%-50 \%$ of patients with deep vein thrombosis, even after adequate treatment ${ }^{8}$. PTS is the most common complication of DVT, and is a risk factor for its recurrence ${ }^{9-11}$. Incidence of CTEPH after PE is $1 \%-4 \%^{12-15}$. These chronic complications reduce quality of life and increase health care costs ${ }^{16,17}$. VTE itself is economically burdensome, associated with significant increases in medical costs, especially those due to recurrence and hospital re-admission ${ }^{18}$.

There is a lack of research in Korea regarding the recurrence of VTE; therefore, our objective was to estimate the cumulative probability of recurrence of VTE after PE, as well as identify possible risk factors for these recurrences in Korea.

\section{Materials and Methods}

\section{Study subject}

From January 2005 to June 2013, 863 adult (PE) patients were consecutively enrolled in a single tertiary hospital, Keimyung University Dongsan Hospital, Daegu in Korea. The currentt study was approved by the institutional review board (IRB) at Keimyung University Dongsan Hospital, Keimyung University School of Medicine (IRB No 2015-06-045). The IRB waived the requirement for informed consent. This study was conducted in compliance with the Declaration of Helsinki. Of the 863 patients with pulmonary embolism, 201 were excluded because they had a follow-up period of less than one month. Recurrence of thromboembolic events was evaluated in the remaining 662 patients.

\section{Follow-up and outcome classification}

Electronic medical records of all PE patients were examined and all recurrent VTE events were noted. The median followup duration was 18.0 months (interquartile range [IQR], 0-49.0 months). Patients were treated with heparin and a vitamin $\mathrm{K}$ antagonist (VKA).

\section{Statistical analysis}

Baseline characteristics at diagnosis of PE (age, sex, body mass index [BMI], presence of risk factors, anticoagulation duration, and comorbidities) for both recurrent cases and nonrecurrent cases were summarized using descriptive statistics (Table 1). A chi-square test was used to compare frequencies of risk factors between recurrent and non-recurrent cases. $\mathrm{Cu}$ mulative recurrence of VTE was estimated using the Kaplan-
Meier method. Cox proportional hazards modeling was performed to evaluate risk factors for recurrence. Second and third recurrent events after the index PE were not included in the cumulative incidence analyses. All statistical analyses were performed by using SPSS version 20.0 (IBM Corp., Armonk, NY, USA); $<<0.05$ was considered to be statistically significant.

\section{Results}

\section{Incidence of recurrent VTE after PE}

Of the total 662 patients with PE, recurrent VTE events were observed in 68 individuals during the follow-up period. Of these, 36 cases were of PE alone, 16 were of DVT alone, and 16 were of PE and DVT. Only one patient had recurrence of VTE during anticoagulation. Median follow-up period was 8.0 months (IQR, 3.0-22.25 months) for active cancer patients and 26.0 months (IQR, 8.0-60.0 months) for non-cancer patients. The 5-year cumulative incidence of recurrent venous thromboembolic events was $21.5 \%$ (95\% confidence interval [CI], 17.7\%-25.4\%) after all PE. The 5-year cumulative recurrent venous thromboembolic rate were $17 \%$ after a provoked PE and 27\% after an unprovoked PE (Figure 1).

\section{Baseline characteristics}

The baseline characteristics of the patients are provided in Table 1. Fifty-two patients had previous history of VTE. The majority of patients with provoked PE were females with a mean age of 65.6 years. Among the 68 patients with recurrent VTE, 53 patients had provoked PE and 15 patients had unprovoked PE. Women, and patients with $\mathrm{BMI} \geq 25 \mathrm{~kg} / \mathrm{m}^{2}$ and symptomatic DVT were higher among patients with recurrent VTE than in those without recurrent VTE. Anticoagulation

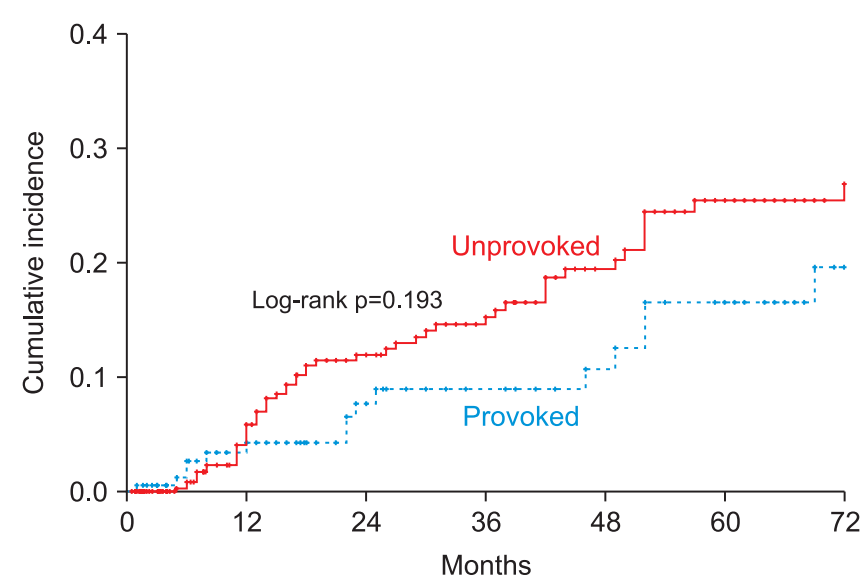

Figure 1. Cumulative incidence of recurrent venous thromboembolism. Unprovoked pulmonary embolism (solid line) vs. provoked pulmonary embolism (dotted line). 
duration was different between the two groups.

\section{Risk of recurrent VTE}

In the multivariate Cox regression analysis, patients with $\mathrm{BMI} \geq 25$ (HR, 2.02; 95\% CI, 1.17-3.46) and longer anticoagulation therapy duration (HR, 0.90; 95\% CI, 0.84-0.96) were significantly associated with risk of recurrent VTE during the follow-up period (Table 2). History of VTE (HR, 1.81; 95\% CI, 0.84-3.88; $\mathrm{p}=0.10$ ), symptomatic DVT (HR, 1.81; 95\% CI, 0.843.88; $\mathrm{p}=0.12$ ), unprovoked PE (HR, 1.70; 95\% CI, 0.89-3.25; $\mathrm{p}=0.10)$, and female sex (HR, 1.42; 95\% CI, 0.78-2.55; $\mathrm{p}=0.24)$ were associated with increased risk of a VTE recurrent event, but these factors did not reach statistical significance at the $\mathrm{p} \leq 0.05$ level. Age, history of cancer, and other co-morbidities did not significantly affect the risk of a VTE recurrent event.

\section{Discussion}

There are four main findings from this study. (1) The cumulative recurrence rate of VTE was $17 \%$ in patients with provoked VTE and $27 \%$ in patients with unprovoked VTE 5 years after anticoagulation therapy. The rates of recurrent

Table 2. Univariate and multivariate analyses for VTE recurrence during follow up period among patients with PE

\begin{tabular}{|c|c|c|c|c|}
\hline \multirow{2}{*}{ Variable } & \multicolumn{2}{|c|}{ Univariate } & \multicolumn{2}{|c|}{ Multivariate } \\
\hline & HR (95\% CI) & p-value & HR (95\% CI) & p-value \\
\hline \multicolumn{5}{|l|}{ Age, yr } \\
\hline \multicolumn{5}{|l|}{$<50$ (reference) } \\
\hline $50-59$ & $0.54(0.20-1.40)$ & 0.20 & $0.44(0.16-1.21)$ & 0.11 \\
\hline $60-69$ & $0.75(0.33-1.71)$ & 0.50 & $0.65(0.27-1.54)$ & 0.33 \\
\hline $70-79$ & $0.89(0.42-1.88)$ & 0.76 & $0.87(0.39-1.97)$ & 0.75 \\
\hline$>80$ & $0.49(0.16-1.48)$ & 0.21 & $0.35(0.09-1.34)$ & 0.12 \\
\hline \multicolumn{5}{|l|}{ Sex } \\
\hline \multicolumn{5}{|l|}{ Men (reference) } \\
\hline Women & $1.49(0.89-2.47)$ & 0.12 & $1.42(0.78-2.55)$ & 0.24 \\
\hline \multicolumn{5}{|l|}{ BMI $\left(\mathrm{kg} / \mathrm{m}^{2}\right)$} \\
\hline \multicolumn{5}{|l|}{$<25$ (reference) } \\
\hline$\geq 25$ & $1.95(1.17-3.24)$ & 0.01 & $2.02(1.17-3.46)$ & 0.01 \\
\hline \multicolumn{5}{|l|}{ Diagnosis } \\
\hline \multicolumn{5}{|l|}{ PE only (reference) } \\
\hline $\mathrm{PE}+\mathrm{DVT}$ & $1.22(0.78-1.91)$ & 0.38 & $0.89(0.52-1.53)$ & 0.68 \\
\hline \multicolumn{5}{|l|}{ Co-morbidity } \\
\hline Heart failure & $1.34(0.70-2.57)$ & 0.36 & $1.54(0.71-3.33)$ & 0.27 \\
\hline Respiratory failure & $0.76(0.47-1.23)$ & 0.27 & $0.91(0.52-1.59)$ & 0.75 \\
\hline Renal dysfunction & $0.77(0.33-1.81)$ & 0.55 & $1.19(0.45-3.10)$ & 0.71 \\
\hline COPD & $0.57(0.14-2.35)$ & 0.44 & $0.75(0.17-3.28)$ & 0.70 \\
\hline Active cancer & $0.61(0.29-1.29)$ & 0.20 & $0.75(0.34-1.65)$ & 0.48 \\
\hline Autoimmune & $0.58(0.08-4.21)$ & 0.59 & $1.14(0.14-8.83)$ & 0.89 \\
\hline Diabetes & $0.74(0.37-1.45)$ & 0.38 & $0.50(0.22-1.12)$ & 0.09 \\
\hline Previous DVT or PE & $1.93(0.96-3.91)$ & 0.06 & $1.81(0.84-3.88)$ & 0.12 \\
\hline Symptomatic DVT & $1.66(1.03-2.68)$ & 0.03 & $1.62(0.89-2.94)$ & 0.10 \\
\hline \multicolumn{5}{|l|}{ Provoked (reference) } \\
\hline Unprovoked & $1.48(0.83-2.64)$ & 0.17 & $1.70(0.89-3.25)$ & 0.10 \\
\hline Anticoagulation duration & $0.93(0.89-0.98)$ & 0.01 & $0.90(0.84-0.96)$ & $<0.01$ \\
\hline
\end{tabular}

VTE: venous thromboembolism; PE: pulmonary embolism; HR: hazard ratio; CI: confidence interval; BMI: body mass index; DVT: deep vein thrombosis; COPD: chronic obstructive pulmonary disease. 
VTE found in this study are comparable to those in previous studies ( $15 \%$ and $30 \%$ respectively) ${ }^{19,20}$. (2) Higher BMI $(\geq 25)$ was associated with higher risk of recurrent VTE. (3) Longer anticoagulation therapy duration was significantly associated with reduced risk of recurrent VTE. (4) History of VTE, unprovoked PE, symptomatic DVT, and female sex were risk factors that trended toward an increased recurrent VTE rate, but they were not statistically significant.

There are a few reports in the literature which make it possible to compare recurrence rates of VTE in Asia with those in Western countries. Lee et al. ${ }^{21}$ report that the cumulative rate of VTE recurrence was $14.4 \%$ at 47 months (4-year) in a nationwide VTE study based on national health insurance in Taiwan. Nakamura et al. ${ }^{22}$ showed that in a warfarin treatment group, symptomatic recurrent VTE from time of randomization to an end point of either 12 months or study closure (overall study period) occurred in 24 of 538 of East Asian patients (4.5\%) (including Korean, Japanese, Chinese, and Taiwanese) versus 122 of 3,854 non-East Asian patients (3.4\%). In a recent meta-analysis, Yamashita et al. ${ }^{23}$ revealed that the absolute risk of recurrent VTE or VTE-related deaths was 3.3\% and 2.6\% with VKA in Asian and non-Asian patients respectively. These findings support the existence of a similar risk of recurrent VTE in Asians as in Caucasians and suggest that appropriate secondary prevention strategies for VTE should be emphasized in Asia.

In this study, a body mass index of $25 \mathrm{~kg} / \mathrm{m}^{2}$ or greater (HR, 2.02; 95\% CI, 1.17-3.46; $\mathrm{p}=0.01$ ) was identified as a risk factor that significantly increased recurrent VTE. Importantly, a BMI of greater than 25 has been significantly associated with recurrent VTE in a dose dependent manner in other studies ${ }^{24}$. Since it has been shown that metabolic syndrome is a risk factor for $\mathrm{VTE}^{25}$, it may be necessary to control obesity to prevent VTE and its recurrence.

It is well known that the longer the duration of anticoagulation therapy, the less the risk of recurrence of $\mathrm{VTE}^{26,27}$. In our study, the longer the duration of treatment, the lower the risk of recurrence of VTE, and the reduction found was similar to previous studies ${ }^{26}$. However, there are studies where prolonged anticoagulant treatment was shown to reduce the risk of recurrence, while the risk of relapse was not different from the start, when the anticoagulant was discontinued ${ }^{28,29}$.

Active cancer is well known as a significant factor for associated with an increased risk for recurrent $\mathrm{VTE}^{30-32}$. However, active cancer patients in the present study did not associated with recurrence of VTE. In this study, median follow-up period was 8.0 months (IQR, 3.0-22.25 months) for active cancer patients and 26.0 months (IQR, 8.0-60.0 months) for non-cancer patients. It was concluded that patients with active cancer died early and recurrent VTE was less due to low survival rate.

In this study, female patients (HR, 1.42; 95\% CI, 0.78-2.55; $\mathrm{p}=0.24$ ) showed a tendency towards an increased risk of recurrent VTE, although it has been previously reported that men have higher risk of recurrent VTE than women ${ }^{33}$. Interestingly, gender was not shown to be an independent predictor of recurrence in the Taiwanese study ${ }^{21}$. Thus, sex may not be a risk factor of recurrent VTE in Asian populations, unlike what has been found in Caucasian populations, but it will be important to explore this idea in well-designed prospective cohort studies.

In our study, history of VTE and unprovoked PE showed only a tendency to increase risk of recurrent VTE, with no statistical significance, although these two factors are considered to be associated with recurrence ${ }^{20}$. Because this study was performed retrospectively, missing data and mis-classification of associated factors could have been responsible for this discrepancy.

This study has some limitations that should be addressed. First, patients were enrolled from a single institute, retrospectively. Second, the oral anticoagulant agent used during the study period was a VKA. This was because the first available direct oral anticoagulant (DOAC), rivaroxaban, was not available before 2013 in Korea. Third, the time in therapeutic range of the international normalized ratio was not available for assessing the degree of quality control in the study. Fourth, antiphospholipid syndrome is an important risk factor for an increased risk for the first and recurrent $\mathrm{VTE}^{34-36}$. However, in this study, the test for antiphospholipid antibody was rarely performed and excluded from the variables for risk factors.

We assessed the recurrence of VTE after anticoagulation therapy in patients with PE. in Korea. Our results warrant the conduct of a new prospective study to clarify the recurrence rates and to further develop a predictive model of recurrent VTE in the era of DOAC.

In conclusion, the recurrence rate of VTE after PE is high in Korea. Patients with higher BMI and shorter anticoagulation therapy duration have a higher risk of recurrent events.

\section{Authors' Contributions}

Conceptualization: Hwang HG, Choi WI. Methodology: Lee B, Lee CW. Formal analysis: Lee B, Lee CW. Data curation: Lee B, Lee CW. Software: Lee B, Lee CW. Investigation: Choi WI. Writing - original draft preparation: Hwang HG, Choi WI. Writing - review and editing: Hwang HG, Choi WI, Lee CW. Approval of final manuscript: all authors.

\section{Conflicts of Interest}

No potential conflict of interest relevant to this article was reported. 


\section{Funding}

This research was supported by the Soonchunhyang University Research Fund. The funders had no role in study design, data collection and analysis, decision to publish, or preparation of the manuscript. This work was supported by the National Research Foundation of Korea (NRF) grant from the Korean Government (MSIP) (No. 2014R1A5A2010008).

\section{References}

1. Heit JA. The epidemiology of venous thromboembolism in the community. Arterioscler Thromb Vasc Biol 2008;28:3702 .

2. Jang MJ, Bang SM, Oh D. Incidence of venous thromboembolism in Korea: from the Health Insurance Review and Assessment Service database. J Thromb Haemost 2011;9:85-91.

3. Cohen AT, Agnelli G, Anderson FA, Arcelus JI, Bergqvist D, Brecht JG, et al. Venous thromboembolism (VTE) in Europe: the number of VTE events and associated morbidity and mortality. Thromb Haemost 2007;98:756-64.

4. Klok FA, Zondag W, van Kralingen KW, van Dijk AP, Tamsma JT, Heyning FH, et al. Patient outcomes after acute pulmonary embolism: a pooled survival analysis of different adverse events. Am J Respir Crit Care Med 2010;181:501-6.

5. Hong J, Lee JH, Yhim HY, Choi WI, Bang SM, Lee H, et al. Incidence of venous thromboembolism in Korea from 2009 to 2013. PLoS One 2018;13:e0191897.

6. Choi WI, Jo JY, Kwon YS, Kim JB, Lee MY. Incidence of pulmonary embolism among hospitalized patients. Thromb Res 2012;129:523-5.

7. Choi WI, Lee MY, Oh D, Rho BH, Hales CA. Estimated incidence of acute pulmonary embolism in a Korean hospital. Clin Appl Thromb Hemost 2011;17:297-301.

8. Ashrani AA, Heit JA. Incidence and cost burden of postthrombotic syndrome. J Thromb Thrombolysis 2009;28:46576.

9. Prandoni P, Kahn SR. Post-thrombotic syndrome: prevalence, prognostication and need for progress. Br J Haematol 2009;145:286-95.

10. Stain M, Schonauer V, Minar E, Bialonczyk C, Hirschl M, Weltermann A, et al. The post-thrombotic syndrome: risk factors and impact on the course of thrombotic disease. J Thromb Haemost 2005;3:2671-6.

11. Kahn SR, Shrier I, Julian JA, Ducruet T, Arsenault L, Miron MJ, et al. Determinants and time course of the postthrombotic syndrome after acute deep venous thrombosis. Ann Intern Med 2008;149:698-707.

12. Pengo V, Lensing AW, Prins MH, Marchiori A, Davidson BL, Tiozzo F, et al. Incidence of chronic thromboembolic pulmonary hypertension after pulmonary embolism. N Engl J Med 2004;350:2257-64.
13. Guerin L, Couturaud F, Parent F, Revel MP, Gillaizeau F, Planquette B, et al. Prevalence of chronic thromboembolic pulmonary hypertension after acute pulmonary embolism: prevalence of CTEPH after pulmonary embolism. Thromb Haemost 2014;112:598-605.

14. Choi WI. Incidence of chronic thromboembolic pulmonary hypertension after pulmonary embolism: a retrospective analysis in a university teaching hospital. Clin Exp Thromb Hemost 2015;2:4-7.

15. Klok FA, Dzikowska-Diduch O, Kostrubiec M, Vliegen HW, Pruszczyk P, Hasenfuss G, et al. Derivation of a clinical prediction score for chronic thromboembolic pulmonary hypertension after acute pulmonary embolism. J Thromb Haemost 2016;14:121-8.

16. Beckman MG, Hooper WC, Critchley SE, Ortel TL. Venous thromboembolism: a public health concern. Am J Prev Med 2010;38(4 Suppl):S495-501.

17. MacDougall DA, Feliu AL, Boccuzzi SJ, Lin J. Economic burden of deep-vein thrombosis, pulmonary embolism, and post-thrombotic syndrome. Am J Health Syst Pharm 2006;63(20 Suppl 6):S5-15.

18. LaMori JC, Shoheiber O, Mody SH, Bookhart BK. Inpatient resource use and cost burden of deep vein thrombosis and pulmonary embolism in the United States. Clin Ther 2015;37:6270.

19. Kearon C, Akl EA, Comerota AJ, Prandoni P, Bounameaux H, Goldhaber SZ, et al. Antithrombotic therapy for VTE disease: Antithrombotic Therapy and Prevention of Thrombosis, 9th ed: American College of Chest Physicians Evidence-Based Clinical Practice Guidelines. Chest 2012;141(2 Suppl):e419S96S.

20. Kearon C, Akl EA, Ornelas J, Blaivas A, Jimenez D, Bounameaux H, et al. Antithrombotic therapy for VTE disease: CHEST Guideline and Expert Panel Report. Chest 2016;149:315-52.

21. Lee CH, Lin LJ, Cheng CL, Kao Yang YH, Chen JY, Tsai LM. Incidence and cumulative recurrence rates of venous thromboembolism in the Taiwanese population. J Thromb Haemost 2010;8:1515-23.

22. Nakamura M, Wang YQ, Wang C, Oh D, Yin WH, Kimura T, et al. Efficacy and safety of edoxaban for treatment of venous thromboembolism: a subanalysis of East Asian patients in the Hokusai-VTE trial. J Thromb Haemost 2015;13:1606-14.

23. Yamashita Y, Morimoto T, Toyota T, Shiomi H, Makiyama T, Ono $\mathrm{K}$, et al. Asian patients versus non-Asian patients in the efficacy and safety of direct oral anticoagulants relative to vitamin $\mathrm{K}$ antagonist for venous thromboembolism: a systemic review and meta-analysis. Thromb Res 2018;166:37-42.

24. Eichinger S, Hron G, Bialonczyk C, Hirschl M, Minar E, Wagner $\mathrm{O}$, et al. Overweight, obesity, and the risk of recurrent venous thromboembolism. Arch Intern Med 2008;168:1678-83.

25. Jang MJ, Choi WI, Bang SM, Lee T, Kim YK, Ageno W, et al. Metabolic syndrome is associated with venous thromboembolism in the Korean population. Arterioscler Thromb Vasc 
Biol 2009;29:311-5.

26. Hansson PO, Sorbo J, Eriksson H. Recurrent venous thromboembolism after deep vein thrombosis: incidence and risk factors. Arch Intern Med 2000;160:769-74.

27. Schulman S, Rhedin AS, Lindmarker P, Carlsson A, Larfars G, Nicol P, et al. A comparison of six weeks with six months of oral anticoagulant therapy after a first episode of venous thromboembolism: duration of Anticoagulation Trial Study Group. N Engl J Med 1995;332:1661-5.

28. Agnelli G, Prandoni P, Santamaria MG, Bagatella P, Iorio A, Bazzan M, et al. Three months versus one year of oral anticoagulant therapy for idiopathic deep venous thrombosis. Warfarin Optimal Duration Italian Trial Investigators. N Engl J Med 2001;345:165-9.

29. Couturaud F, Sanchez O, Pernod G, Mismetti P, Jego P, Duhamel E, et al. Six months vs extended oral anticoagulation after a first episode of pulmonary embolism: the PADIS-PE Randomized Clinical Trial. JAMA 2015;314:31-40.

30. Chee CE, Ashrani AA, Marks RS, Petterson TM, Bailey KR, Melton LJ 3rd, et al. Predictors of venous thromboembolism recurrence and bleeding among active cancer patients: a population-based cohort study. Blood 2014;123:3972-8.

31. Hutten BA, Prins MH, Gent M, Ginsberg J, Tijssen JG, Buller HR. Incidence of recurrent thromboembolic and bleeding complications among patients with venous thromboembolism in relation to both malignancy and achieved international normalized ratio: a retrospective analysis. J Clin Oncol 2000;18:3078-83.

32. Prandoni P, Lensing AW, Piccioli A, Bernardi E, Simioni $\mathrm{P}$, Girolami B, et al. Recurrent venous thromboembolism and bleeding complications during anticoagulant treatment in patients with cancer and venous thrombosis. Blood 2002;100:3484-8.

33. Olie V, Zhu T, Martinez I, Scarabin PY, Emmerich J. Sexspecific risk factors for recurrent venous thromboembolism. Thromb Res 2012;130:16-20.

34. Garcia D, Akl EA, Carr R, Kearon C. Antiphospholipid antibodies and the risk of recurrence after a first episode of venous thromboembolism: a systematic review. Blood 2013; 122:817-24.

35. Farmer-Boatwright MK, Roubey RA. Venous thrombosis in the antiphospholipid syndrome. Arterioscler Thromb Vasc Biol 2009;29:321-5.

36. Na YS, Jang S, Hong S, Oh YM, Lee SD, Lee JS. Clinical phenotype of a first unprovoked acute pulmonary embolism associated with antiphospholipid antibody syndrome. Tuberc Respir Dis 2019;82:53-61. 